\title{
Flavonoids in the development of functional meat products: A review
}

\author{
Pavan Kumar ${ }^{1}$, Sunil Kumar ${ }^{1}$, M.K.Tripathi ${ }^{2}$, Nitin Mehta ${ }^{3}$, Rajeev Ranjan ${ }^{4}$, Z. F. Bhat ${ }^{1}$ and Pramod K. Singh ${ }^{1}$
}

1. Department of Livestock Products Technology, College of Veterinary Science, Guru Angad Dev Veterinary and Animal Science University, Ludhiana, Punjab, India; 2. Division of VPB, Faculty of Veterinary Science and animal Husbandry, SKUAST, Jammu, India; 3. Department of Food Science \& Technology (Animal Products Technology) NIFTEM, Sonipet, Haryana, India; 4. Department of VPT, College of Veterianry Science, LLRVAU, Hissar, Haryana, India

Corresponding author: Pavan Kumar, email:vetpavan@gmail.com

Received: 21-02-2013, Revised: 07-03-2013, Accepted: 08-03-2013, Published online: 14-06-2013

\section{How to cite this article:}

Kumar P, Kumar S, Tripathi MK, Mehta N, Ranjan R, Bhat ZF and Singh PK (2013) Flavonoids in the development of functional meat products: A review, Vet World 6(8): 573-578, doi:10.5455/vetworld.2013.573-578

\begin{abstract}
Flavonoids or bioflavonoids are unique low molecular weight ubiquitous polyphenolic compounds produced by plants during their metabolic activities as a secondary metabolites and responsible for major organoleptic characteristics and health benefits of plant derived foods. The flavonoids are potent antioxidants agents and protect the cells by scavenging and inhibiting the production and initiation of free radicals, superoxide anions and lipid peroxy radicals. Besides potent antioxidant capacity, flavonoids also shows antimicrobial, antimutagenic, antidiabetic, antithrombosis, antirheumatic, antiatherosclerotic, antiallergic, anti-inflammatory, antiulcers and hepatoprotectives and better termed as neutraceuticals. The antioxidant capacity of meat is very low and this can be increased by adding flavonoids in meat during processing in the form of plant parts rich in flavonoids such as seeds, fruit skin or peel, bark and flower as raw or in extract form without comprising the sensory attributes of meat and meat products.
\end{abstract}

Keywords: antioxidants, flavonoids, functional meat products, grape seed, green tea, rosemary,

\section{Introduction}

The concept of functional foods was first come in practice in 1980s in Japan for the foods comprising certain constituents having beneficial effect on health. The FOSHU concept (Food for Specified Health Use) came into use in 1991 in Japan for the foods which are based on knowledge of relationship between foods or food components and health are expected to have certain health benefits and have been licensed to bear labelling claiming that a person using them may except to obtain the health use through the consumption of these foods. This ever increasing awareness of consumers about healthy foods has forced the food industries to develop new foods with positive health benefits $[1,2]$. The emphasis is on adding the functional value to food (tertiary function), besides basic function of providing nutrients (primary function) as well as satiety of senses (secondary function). These functional foods should have technologically developed ingredients with specific health benefits in a significant amount of biologically active compounds which influence specific beneficial function in the body.

The nutritive value of meat is very high due to presence of high quality protein, vitamins, minerals and fat [1] and plays a pivotal role in alleviating malnutrition in developing world [3]. The lack of inherent antioxidant and available of high quality nutrients leads to the problem of perishability of the meat and meat products [4,5]. The inherent antioxidants capacity of meat products is very low

This article is an open access article licensed under the terms of the Creative Commons Attribution License (http://creativecommons. org/licenses/by/2.0) which permits unrestricted use, distribution and reproduction in any medium, provided the work is properly cited. leading to concern about the quality and shelf life of meat and meat products. The antioxidants play a major role in checking the oxidation of fat as well reducing the harmful free radicals just protecting the cells from damage. By improving the antioxidant capacity of meat by adding natural antioxidants such as flavonoids, the overall quality as well as acceptability of meat and meat products can be further enhanced. The meat products prepared from low value cuts and offal have poor cooking yield and emulsion stability due to higher collagen content leads to poor emulsifying and water binding capacity these cuts. By adding the plant based binders and extender, the binding as well as functional value of meat products increased [6].

Phytochemicals such as phenolics, anthocyanins and other flavonoids prevent the occurrence of certain chronic diseases in plants while maintaining the freshness in fruits and prolonging the food storage and these natural compounds present in plant have strong antioxidant capacity [7]. The amount of these antioxidants depends upon the irradiation, plant tolerance against microbes and stage of maturity of plant [8-10]. Flavonoids are unique novel molecules possessing strong antioxidant capacity. Meat and meat products are devoid of flavonoids which can be taken care of by adding the fruit, vegetables or the by-products of fruit industry. By adding these products, meat and meat products become rich in antioxidants and increases the value of meat. Flavonoids are the major class of ingredients to be added in food to increase the antioxidants activities as well as other therapeutic value of food.

\section{Flavonoids as nutraceuticals}

Flavonoids or bioflavanoids are widely distributed 
Table-1. Classification of flavonoids and their dietary source (source: $[11,13,14]$ )

\begin{tabular}{|c|c|c|c|}
\hline Class & Characteristics & Example & Dietary source \\
\hline Flavonol & 3-Hydroxy-2-phenyl-chromen-4-one & Quercetin, rutin, kaempherol, myrecetin & $\begin{array}{l}\text { Tea, tomato, red wine, apple, cherry, } \\
\text { onion }\end{array}$ \\
\hline Flavanol & & Catechin, gallocatechin & Tea, apple \\
\hline Flavone & 2-Phenyl-chromen-4-one & $\begin{array}{l}\text { Apegenin, chrysin, luteolin, myrecetin, } \\
\text { sibelin }\end{array}$ & $\begin{array}{l}\text { Berries, fruit peels,grape, parsley, } \\
\text { olives, lettuce, cranberries }\end{array}$ \\
\hline Isoflavone & 3-Phenyl-chromen-4-one & Genestein, glycitein, daidzein, formononetin & Legume \\
\hline Flavanone & 2-Phenyl-chroman-4-one & Hesperidin, Narigenin & Grape, orange, berries, red wine \\
\hline Flavanonol & 3-Hydroxy-2-phenylchroman-4-one & Taxifolin & Lemon, sour orange \\
\hline
\end{tabular}

in plant kingdom, modulating the human metabolism for prevention of chronic and degenerative diseases. The flavonoids were first noticed by Hungarian scientist Albert Szent-Gyorgi in 1936 and termed as citrin or vitamin $\mathrm{P}$ to explain the synergy between pure vitamin $\mathrm{C}$ and as yet unidentified co-factors from the peels of lemons [11]. Till now, more than 4000 such molecules have been identified from fruits, vegetables and beverages. Flavonoids are produced in plants via the flavonoid branch of the phenylpropanoid and acetate-malonate metabolic pathway. Flavonoids are the phenolic compounds comprising the general structure of flavan nucleus phenyl benzopyrone skeleton (C-3C-6C-3) in all molecules and having a chromane type skeleton having phenyl substituent in C2-C3 position. The basic structural feature of flavonoid is 2-phenyl-benzo- $\gamma$-pyrane nucleus made up of two benzene rings (A and B) linked through a heterocyclic pyran ring $(C)$ [12].The ring synthesized in polyacetate pathway whereas, $\mathrm{B}$ and $\mathrm{C}$ rings in shikimate pathway. The different classes of flavonoids have been categorized based on the oxidation status of central ring C. Anthocyanidins are produced by oxidation and reduction gives rise to flavon-3-ols and flavan-3,4-diols. Intermediate compounds such as flavanones, flavonols and flavones produces based on the presence or absence of the double bond between C2-C3 molecules.

There are three major classes of flavonoids viz. flavones, isoflavonoids, neoflavonoids. Flavones are derived from 2-phenyl-1,4-benzopyrene derivatives such as quercetin and rutin. Isoflavanoids are derivatives of 3-phenyl-1,4-benzopyrene where being derived from neoflavanoids 4-phenyl-1,4-benzopyrene.

\section{Flavonoids as potent natural antioxidants}

The flavonoids exhibit the beneficial effect due to the antioxidants and chelating properties of these molecules by prevent the free radicals to damage the biological molecules like lipid, protein, sugar, DNA, RNA etc. The free radicals are having at least one free electron in their outer orbit and produced from ionization of oxygen such as reactive oxygen species (ROS) superoxide anion, hydroxyl and peroxyl radicals. These radicals causes cell death by attacking on deoxyribose and nitrogen bases, breaking the DNA strands and accumulation of mutations. These damage the proteins by attacking sulphydryl groups and disulphide bonds or by nitration of aromatic amino acids [15-17]. Utilization of plant extracts as an alternative to chemical or synthetic antimicrobials and antioxidants to control the food borne diseases, inhibiting lipid oxidation and thus extending the shelf life and quality of food products is an increasing trend in the food industry [18].

Based on the source of origin, antioxidants can be divided into two types viz. natural antioxidants (flavonoids) and synthetic antioxidants (BHA, BHT, $\beta$ carotene, vitamin $\mathrm{C}$, vitamin $\mathrm{E}$ ). The synthetic antioxidants increase the risk of mortality in adult due to rigorous toxicity and increasing risk of cancer that they have as compared to natural antioxidants [19]. The antioxidants activity of the flavonoids is superior to the synthetic antioxidants. The larger intake of these plants in our diet further improves overall their antioxidant capacity. The flavonoids prove better alternative to vitamin $\mathrm{E}$ in meat and meat products. The antioxidants activity is assessed by evaluating their scavenging the capability against artificial radicals such as 2-2'azinobis-3-ethylbenzothizoline- 6-sulfonic acid (ABTS), 1-1'-diphenyl 2-picrylhydrazyl (DPPH) and N,N-dimethyl-p-phenylendiamine (DMPD) [20]. The antioxidants activity is mainly due to the high reactivity of their hydroxyl groups especially present on ring $\mathrm{B}$ towards free radicals and the flavonoids devoid of hydroxyl groups such as flavones, flavanones and isoflavones shows little antioxidant activities. The presence of hydroxyl group at 3 position results in 10 times more antioxidant capacity. The double bond at $\mathrm{C} 2-\mathrm{C} 3$ enhances the antioxidant activity. The antioxidant capacity of the flavonoids are having the following order as flavanols $>$ flavonols $>$ chalcones $>$ flavones $>$ isoflavones, except the quercetin [21].

Intake of cranberry juice at $7 \mathrm{mg} / \mathrm{kg}$ of body weight for two weeks to 21 men decreased the level of circulatory plasma oxidized LDH with an increase in antioxidant activity [22]. The intake of red wine phenolic extracts as well as grape polyphenols showed positive effect in reducing the blood plasma cholesterol and triglycerides levels. This is due to the free radical scavengering as well as metal chelating capacity of these flavonoids. The free radical scavenging ability of flavonoids is due to the hydrogen donating capacity. Flavonoids also inhibit the enzymes directly linked in the production of free radicals such as xanthine oxidase, lipooxygenase and cyclooxygenase and NADH oxidase, under oxidative stress and lipid peroxidation. The presence of a hydroxyl group at positions C-3 and C-3' are equally important for high 
superoxide scavenger activity. Membrane partitioning and lipophilicity seem to play a role in protecting the lipids in membrane from lipid peroxidation and flavonoids protect and maintain the integrity of membrane by controlling the membrane fluidity [23]. Flavonoids inhibit the activity of enzyme protein kinase $\mathrm{C}$ (PKC) by competitive binding with the ATP at catalytic sites on the enzyme. PKC is responsible for inducing the growth of tumor cells by inducing mitogenesis, secretory processes, inflammatory cell functions and T lymphocyte function. Protoanthocyanidins largely present in cranberry and blueberry fruits shows antitumor activities by inhibit LDH oxidation and protecting the neurons and vascular endothelium [24]. The extracts of cranberry and blueberry fruits inhibits ornithine decarboxylase expression and induce quinine reductase, inhibit the proliferation of MCF-7 and MDA-MB 435 breast cancer cells. Quercetin shows anti-proliferative and anticancer activities by induction of apoptosis with G1 phase arrest, reduced Ras protein expression, inhibited significantly the growth of MCF-7 breast adenocarcinoma, HT-29 human colon adenocarcinoma and K-562 human chronic myelogenous leukaemia cell line as well as HepG2 liver cancer cells.

Flavonoids protect the heart and pancreas from diseases by inhibiting LDH peroxidation and alleviating the oxidative stress. Flavonoids control the blood pressure by inhibiting the ACE (angiotensin converting enzyme) which helps in converting angiotensin I to angiotensin II. Angiotensin II is a potent vasoconstrictor and limiting the conversion of angiotensin I to angiotensin II by inhibiting the ACE. This is also complemented by preventing the nitric oxide degradation by free radicals. Flavonoids also show anti-thrombotic activity by significantly inhibiting the adhesion, aggregation and secretion of platelets. Hygrophila spinosa is a commonly found herb in India rich in flavonoids, tannins, alkaloids and essential oils It is widely used in treatment of jaundice, renal disorders, hepatic dysfunction and inhibiting metastasis of cancer cells [25]. Aloe vera contains phytochemicals such as flavonoids, saponins etc which is indication of cosmetic and medicinal value [26]. Pineapple extract in ethyl acetate, methanol and water were found to have antioxidant capacity comparable to ascorbic acid and BHA due to presence of phenolic compounds in it [27]. Phytoestrogens are secondary plant metabolites, structurally or functionally similar to $17-ß e s t r a d i o l$ have potentially beneficial effects as estrogen agonists or anti-estrogens in health and disease. The major classes of phytoestrogens are isoflavones, lignans, and coumestans. Legumes especially soybeans, whole grain cereals, and some seeds are high in phytoestrogen [28].

\section{Use of flavonoids in meat and meat products}

During the preparation of various meat products, the flavonoids have been added to increase the antioxidant capacity of meat as well as to make these products safer. One of the common practices is to add vegetables, fruit, fruit by products as well extracts of various medicinal plants into meat during preparation of meat products. The addition of bell pepper, carrot, grape pulp with skin and seed, knot-cabbage, green and black tea, lemon, lotus stem etc within suitable ranges increases the quality and yield of the meat products. Various legumes are rich source of flavonoids beside good source of protein, carbohydrate, vitamins and minerals. The incorporation of various legumes at suitable levels in food products including meat products enhances the cooking yield, emulsion stability as well as functionality of these products [29]. These products are reported enhance dietary fibers as well as antioxidant properties in meat product.

Rosemary: Rosemary is a bushy evergreen shrub widely used in culinary and medicinal ingredients. The antioxidant properties of rosemary extracts are very high due to the presence of high levels of phenolic compounds in it and the antioxidant capacity is equivalent to the BHA and BHT. These compounds are capable of regenerating endogenous tocopherol in the phospholipid bilayer of lipoprotein [30]. The rosemary extract at $2500 \mathrm{ppm}$ delays TBRAS (thiobabituric acid reacting substances) values in raw and precooked sausage during refrigerated and frozen storage besides improving colour and freshness [30] and proves to a better alternative BHA and BHT. The antioxidant activity of a number of flavonoid and flavonoid-related phenolic acids in relation to stability of meat lipids was evaluated in meat model systems over a three-week storage period by and found that morin, myricetin, kaempferol and quercetin at a level of $200 \mathrm{ppm}$ were most active leading to TBA (2-thiobarbituric acid) values of less than $0.55 \mu \mathrm{g}$ malondialdehyde equivalents/g sample after a 21 -day storage at $4{ }^{\circ} \mathrm{C}$. The activity of phenolic acids belonging to the hydroxybenzoic and caffeic acid families was moderate with a $24-69 \%$ inhibition of formation of TBA reactive substances. The large scale production of fruit byproducts possesses a serious problem of their disposal and leads to environmental pollution. These fruit byproducts are very rich source of flavonoids and other health promoting materials. By processing and introducing newer technology, it is possible to use these fruit by-products such as skin, seed, peels etc in meat products. By adding these by-products to the meat products in a suitable amount, the quality of meat products improved significantly and the storage of such meat products has improved.

The incorporation of rosemary extract in cooked turkey products leads to decreased lipid oxidation and improved colour loss as noticed by decreased $\mathrm{L}$ value and increased a value during refrigerated storage [31]. Nam et al [32] reported the significantly reduced volatile hexanal without inducing any effects on the production of sulphur volatiles in irradiated pork loins upon adding rosemary oleoresin with tocopherol. Rosemary extracts 
improved the colour of meat by reducing the metmyoglobin concentration and increasing the oxymyoglobin values during $8^{\text {th }}$ storage in irradiated minced beef [33]. The colour of meat and meat products is a very important factor playing an important role in marketing and consumer acceptability of these products. The appearance of bright red colour of oxymyoglobin (bloom) of fresh meat is preferred whereas brown or black colour is not preferred by the consumers. The oxidation of lipids leads to deterioration in colour, flavour, texture and compromised nutritional value of meat products. This lipid oxidation can be delayed or prevented by adding natural or synthetic antioxidants in meat and meat products. The synthetic antioxidants are not well accepted by the consumers due to health concerns [34]. In Asian countries, various natural ingredients such as herbs, condiments and spices being rich source of natural oxidants as polyphenolics, diterpenes, flavonoids, tannins and phenolic acids, are increasingly added in meat and meat products to control the lipid oxidation $[35,36]$. Oil of cloves or clove oil is obtained from clove plant Syzygium aromaticum from bud, leaf and stem. It is colourless and pale yellow in colour and increasingly being added in the meat seasoning and flavouring of food products including meat products. It shows antibacterial and antiseptic activities against important human pathogens [37]. It has strong antioxidant activity among all spices. The antimicro-bial activity of spices is attributed to the phenolic compounds which alter the cell membrane permeability of bacteria [38]. A significant decrease in the level of E. coli $\mathrm{O} 157: \mathrm{H} 7$ in cooked beef patties have been noticed with $5 \%$ olive or apple skin extract and clove bud oil reduced the pathogen by $1.6 \log \mathrm{CFU} / \mathrm{g}$ [39]. The shelf life of chicken pickle and nuggets has been reported to increase by adding clove oil in these products during storage.

Green tea: Green tea is a non-fermented tea. Green tea is full of antioxidants to about $30 \%$ of its dry weight. Green tea extract has been reported to decrease the level of carcinogenic heterocyclic amines in pan fried beef and marinating the meat with green tea did not compromised the sensory characteristics of grilled meat [40]. The addition of $0.5-2 \%$ of green tea leave extracts have been reported to significantly decrease the levels of Clostridium perfringens in cooked ground beef, chicken and pork during abusive cooling [41]. Green tea produced from the leaves of Camellia sinensis and contains catechin flavonoids including catechin and epicatechin and gallic acid esters. The most common flavonoids in green tea is epigallocatechin gallate where as black tea contain more free gallic acid. Catechin is a predominant group of polyphenols present in green tea leaves composed of four compounds epicatechin, epicatechin gallate, epigallocatechin and epigallocatechin gallate [42]. These compounds promote health by preventing lipid oxidation and providing antibacterial, anticarcinogenic and antiviral ability $[43,44]$. The catechins reduce the level of peroxides even more effectively than vitamin $\mathrm{E}$ and BHA in porcine lard and chicken fat [45]. The addition of tea catechin at $300 \mathrm{ppm}$, significantly reduce the TBRAS values of beef, duck, ostrich, pork and chicken during refrigerated storage and proves to have 2-4 times more efficient than vitamin $\mathrm{E}$ in different meat [46]. The catechins reduce the production of putrescine and tyramine in dry fermented pork sausage. The addition of green tea do not affect the $\mathrm{pH}$, colour and overall senory quality of sausages [47]. The nitrite is added during formation of meat products to get stable colour, antioxidant and Antibotulinum effect. In pork sausage, the green tree powder have been added to partly substitute and found the lower TBRAS value and decreased volatile basic nitrogen contents $[48,49]$ and in Turkish dry fermented sausage, sucuk more efficiently than synthetic antioxidants [47].

Grape seed: Grape seed extract (GSE) is a by-product derived from the grape seeds (Vitis vinifera) that is extracted, dried and purified to produce a polyphenolic compound rich extract [50]. Grape seed extracts (GSE) has been used in meat industry to enhance the antioxidant capacity of meat. It inhibit the oxidation products from primary lipids (lipid hydroperoxides and hexanal) and secondary lipids (thiobarbituric acid reactive substances) [51]. The grape seed extract has been shown to improve flavour by reducing the rancid flavour in meat products raw beef, cooked beef, cooked pork patties, turkey, fish oil, frozen fish and grounded chicken breast and thigh meat without change in $\mathrm{pH}$, yield and water activity [51-54 ]. In pork, the clear antioxidant effect was observed at $400 \mu \mathrm{g} / \mathrm{g}$ and $0.1 \%$ $(\mathrm{w} / \mathrm{w})$ in ground chicken to reduce the TBARS [50]. Grape seed extract at $0.1 \%(\mathrm{w} / \mathrm{w})$ reduce TBRAS and hexanal in beef, chicken, turkey and raw and cooked meat system and minor increase in the retention of red colour [54-57]. The citrus industry is growing very rapidly world wide. These fruits are having a comparatively small edible part and larger inedible part. Thus the production of by-products in the citrus industry is very large. The by-products of the citrus industry are full of nutritive compounds such as flavonoids, polyphenols, vitamins, proteins, oil, lipids and minerals. Previously these by-products are very rarely used and disposed. This damage the fragile environment and causes environmental pollution. The amount of total polyphenolic compounds are more in whole fruit than peeled fruit and in the peel than in peeled part. The outer skin/ peel/ covering of citrus fruits are showing higher concentration of flavonoids. The flavonoid content is highest in lemon followed by orange and grape fruit amongst the citrus fruits. The main citrus flavonoids are hysperidine, narirutin and naringen.

Recommended Dietary Allowance (RDA): The flavonoids play major role in antioxidant system of our body due to the average daily intake of flavonoids ranges from 
50-800 $\mathrm{mg}$ in comparison to the average daily intake of vitamin C (70 mg), vitamin E (7-10 mg) or carotenoids (2-3 mg) depending upon the consumption of fruits, vegetables and beverages in the diet. The RDA of flavonoids is not fixed. For supplementation, $500 \mathrm{mg}$ flavonoids per day are recommended. As the flavonoids show synergistic reactions with Vitamin C, so the use of flavonoids should be with vitamin C. For getting the therapeutic and health promoting benefits, a minimum 50- $500 \mathrm{mg}$ of flavonoids should be consumed per day. The acidity, boiling and processing of food causes upto $50 \%$ destruction of flavonoids. Flavonoids content in fruit and vegetables can reach as high as $300 \mathrm{mg} / \mathrm{kg}$ fresh weight and human consume between 20 and $80 \mathrm{mg}$ flavonoids per day [58].

\section{Concerns}

Due to the wide spread of flavonoids in our diet, a significant quantity of flavonoids is consumed by us daily. The average daily consumption of flavonoids in Indian diet is about 1-2 gram per day out of which the average intake of flavonols and flavones accounts about $23 \mathrm{mg} /$ day. The average consumption of quercetin accounts $16 \mathrm{mg} /$ day [11]. The lowest intake of flavonoids has been reported in Finland and highest in Japan. The amount of flavonoids consumption is depend on the nature of diet, use of fruits, tea etc. There are some reports confirming that the very high intake of flavonoids lead to a less severe toxicity. Animals are more resistant to this toxicity. For rat, the $\mathrm{LD}_{50}$ is 2- 10 gram per animal for most flavonoids. However such type of diet with 2-10 gram flavonoids is unrealistic in normal conditions. For precaution, [59] recommended the daily intake of less than $1 \mathrm{mg}$ per adult per day for human beings. In human, the excess intake of flavonoids leads to diarrhoea due to the problem in digestion.

\section{Conclusion}

There is increasingly trend in the population to prefer meat and meat products with natural compounds in comparison to the synthetic compounds. Meat is naturally low in antioxidants. The flavonoids being the rich source of natural antioxidants and other health benefits such as cardioprotective, anti-carcinogenic, anti-inflammatory, antimicrobial, antiplatelet, antithrombotic, antihypertensive, proper functioning of neurons, liver and kidney. The flavonoids are proved to be a suitable group of polyphenols to be added in meat and meat products without comprising their organoleptic quality. The storage life of flavonoids added meat and meat products are longer due to the free radical scavenger, metal binder and anti-lipid peroxidation capacity of these molecules. The flavonoids would be tomorrow's molecules for use in therapy against certain diseases and as diet supplements for food preservation.

\section{References}

1. Mallika, N. E., Prabhakar, K. and Reddy, P. M. (2009) Low Fat Meat Products - An Overview, Vet. World, 2(9):364-366.
2. Lanjewar, R. D., Zanzad, A. A., Ramteke, Lalmuanpuii., B. N., Taksande, P. E. and Patankar, R. B. (2009). Incorporation of Tulsi (Ocimum sanctum) leaf powder in diet of broilers for quality meat production, Vet. World, 2(9):340-342.

3. Deogade, A. H., Zanjad, P. N. and Raziuddin, M. (2008). Value Added Meat Products, Vet. World, 1(3): 88-89.

4. Das, A., Ranjan, D., Nath, M. H. and Laskar, S. K. (2013) Studies on certain quality attributes of meat pickle prepared from spent chicken, Vet. World, 6: 156-158. doi:10.5455/ vetworld.2013.156-158.

5. Gupta, S. and Savalia, C. V. (2012). Application of biotechnology in improving livestock products, Vet. World, 5(10) 634-638.

6. Ruban, S. W., Kalaikannan, A. and Rao, V. A. (2009) Physico-Chemical Characteristics of Pork Sausageduring Refrigerated Storage, Vet. World, 2(3):95-97.

7. Hue, S. M., Boyce, A. N. and Somasundram, C. (2011) Antioxidant activity, phenolic and flavonoid contents in the leaves of different varieties of sweet potato (Ipomoea batatas), Aust.J. Crop Sci., 6(3): 375-380.

8. Kacharava, N., Chanishvili, S., Badridze, G., Chkhubianishvili, E. and Janukashvili, N. (2009) Effect of seed irradiation on the content of antioxidants in leaves of Kidney bean, Cabbage and Beet cultivars. Aust. J. Crop Sci.3(3): 137-145.

9. Nantitanon, W., Yotsawimonwat S., Okonogi S. (2010) Factors influencing antioxidant activities and total phenolic content of guava leaf extract. LWT-Food Sci. Technol., 43: 1095-1103.

10. Osiru, M. O., Olanya, O. M., Adipala, E., Kapinga R. and Lemaga, B. (2009) Yield stability analysis of Ipomoea batatas L. cultivars in diverse environments, Aust. J. Crop Sci., 3(4): 213-220.

11. Sandhar, H. K., Kumar, B., Tiwari, P., Salhan, M. and Sharma, P. (2011) A review of phytochemistry and pharmacology of flavonoids, Internationale Pharmaceutica Sciencia, 1(1): 25-41.

12. Cushnie, T. P. T. and Lamb A. J. (2005). Antimicrobial activity of flavonoids, Int. JAntimicrobial Agents, 26:343-356.

13. Tapas, A. R., Sakarkar, D. M. and Kakde, R. B. (2008) Flavonoids as nutraceuticals: A review, Tropical $J$ Pharm Res, 7 (3): 1089-1099.

14. United State Department of Agriculture (2011) USDA Database for the Flavonoid Content of Selected Foods. Edt Seema Bhagwat, David B. Haytowitz and Joanne M. Holde, Nutrient Data Laboratory, West Maryland, USA.

15. Aron, P. M. and Kennedy, J. A. (2008) Flavan-3-ols: nature, occurrence and biological activity. Mol Nutr Food Res, 52: 79-104.

16. Brunet, A. (1998) Signal transduction from membrane to the nucleus: variation on common themes, Bull Cancer, 85(6): 527-37.

17. Januel, C., Fay, L. B., Ruggiero, D., Lagarde, M. and Vericel, E. (2003) Covalent coupling of reduced glutathione with ribose: loss of co-substrate ability to glutathione peroxidise, Biochem Biophys Acta, 1620(1): 125-32.

18. Perumalla, A. V., Navam, S. and Hettiarachchy, S. (2011) Green tea and grape seed extracts- Potential applications in food safety and quality, Food Res Int 44: 827-83.

19. Bjelakovic, G., Nikolova, D., Gluud, L. L., Simonetti, R. G. and Gluud, C. (2007). Mortality in randomized trials of antioxidant supplements for primary and secondary prevention: systematic review and meta-analysis, $J$ Amr Med Med Ass (JAMA) 297(8): 842-85.

20. Heim, K. E., Tagliaferro, A. R. and Bobilya, D. J. (2002) Flavonoid antioxidants: chemistry, metabolism and structure-activity relationships, J Nutr Biochem, 13(10): $572-84$

21. Cai,Y., Sun, M., Xing, J., Luo, Q. and Corke, H. (2006) Structure-radical scavenging activity relationships of phenolic compounds from traditional Chinese medicinal plants, Life Sci, 78: 2872-88.

22. Cao, W., Myers-Powell, B. A. and Braciale T. J. (1994) Recognition of an immunoglobulin VH epitope by influenza 
virus-specific class I major histocompatibility complexrestricted cytolytic T lymphocytes, J Exp Med, 179(1): 195-202.

23. Spasojevic, I., Maksimovic, V. and Bqsic, G. (2005) 5Fluorouracil effects on erythrocytes in relation to its cardiotoxicity Membrane structure and functioning, JChem Inform Model, 25: 1680-85.

24. Neto, C. C., Sweeney-Nixon, M. L., Lamoureaux, T. L. and Solomon, F. (2005) Cranberry phenolics: Effects on oxidase processes, neuron cell death and tumor cell growth. Phenolic compounds in foods and natural health products, Washington, DCACS pp 271-82.

25. Mandal, S., Dutta, G. K. and Nath, S. (2010). Qualitative phytochemical screening ofHygrophila spinosa plant extract, Vet World, 3(8): 367-368.

26. Eevuri, T. R. and Putturu, R. (2013) Use of certain herbal preparations in broiler feeds- A review. doi:10.5455/ vetworld.2013.172-179.

27. Hossaina, M. A. and Mizanur, S. M. R. (2011) Total phenolics, flavonoids and antioxidant activity of tropical fruit pineapple, Food Res Int, 44(3): 672-676.

28. Kariyil, B. J. (2010) Phytoestrogen in animal origin foods. Vet World, 3(1):43-45

29. Ren, Shun-Cheng., Liu, Ze-long and Wang, P. (2012) Proximate composition and flavonoids content and in vitro antioxidant activity of 10 varieties of legume seeds grown in China, JMedicinal Plants Res, 6(2): 301-308.

30. Sebranek, J. G., Sewalt, V. J. H., Robbins, K. L. and Houser, T. A. (2004) Comparison of a natural rosemary extract and BHA/BHT for relative antioxidant effectiveness in pork sausage, Meat Sci, 69: 289- 296.

31. Yu, L., Scanlin, L., Wilson, J. and Schmidt, G. (2002) Rosemary extracts as inhibitors of lipid oxidation and color change in cooked turkey products during refrigerated storage JFood Sci 67: 582- 585.

32. Nam, K. C., Ko, K. Y., Min, B. R., Ismail, H., Lee, E. J. and Cordray, J. (2006) Influence of rosemary- tocopherol/ packaging combination on meat quality and the survival of pathogens in restructured irradiated pork loins, Meat Sci, 74: 380- 387.

33. Formanek, Z., Lynch, A., Galvin, K., Farkas, J. and Kerry, J. P. (2003) Combined effects of irradiation and the use of natural antioxidants on the shelf-life stability of over wrapped minced beef, Meat Sci, 63: 433- 440.

34. Achinewhu, S. C., Ogbonna, C. C., Hart, A. D. (1995) Chemical composition of indigenous wild herbs, spices, fruits, nuts and leafy vegetables used as food, Plant Foods Human Nutri, 48, 341- 348.

35. McCarthy, T. L., Kerry, J. P., Kerry, J. F., Lynch, P. B. and Buckley, D. J. (2001) Assessment of the antioxidant potential of natural food and plant extracts in fresh and previously frozen pork patties, Meat Sci, 57: 177- 184.

36. Dawidowicz, A. L., Wianowska, D. and Baraniak B. (2006) The antioxidant properties of alcoholic extracts from Sambucus nigra L. (antioxidant properties of extracts), LebensmittelWissenschaft Technologic, 39:308-315.

37. Vanit, S., Suppakul, P. and Jinkarn, T. (2010) Antimicrobial effects of coating solution containing clove oil and hydrophobic starch for coating paperboard, As J Food $A g$ Ind, 3(2): 204-212.

38. Bajpai, V. K., Rahman, A., Dung, N. T., Huh, M. K. and Kang, S. C. (2008) In vitro inhibition of food spoilage and food borne pathogenic bacteria by essential oil and leaf extracts of Magnolia liliflora Desr, J Food Sci, 73: 314- 320.

39. Rounds, L., Havens, C. M., Feinstein, Y., Friedman, M. and Ravishankar, S. (2012) Plant extracts, spices, and essential oils inactivate Escherichia coli $\mathrm{O} 157: \mathrm{H} 7$ and reduce formation of potentially carcinogenic heterocyclic amines in cooked beef patties, J Agric Food Chem, 60(14):3792-9.

40. Quelhas, I., Petisca, C., Viegas, O., Melo, O., Pinho, A. and Ferreira, I.M.P.L.V.O. (2008) Influence of green tea marinades on the formation of heterocyclic aromatic amines and flavour of pan-fried beef, J Agri Food Chem, 56 (22), 10625-10632.
41. Juneja, V. K., Bari, I. M. L., Inatsu, Y., Kawamoto, S. and Friedman, M. (2007) Control of Clostridium perfringens Spores by Green Tea Leaf Extracts during Cooling of Cooked Ground Beef, Chicken, and Pork, J Food Protect, 70(6): 1429-1433.

42. Zhong, R. Z., Tan, C. Y., Han, X. F., Tang, S. X., Tan, Z. L. and Zeng, B. (2009) Effect of dietary tea catechins supplementation in goats on the quality of meat kept under refrigeration, Small Ruminant Res, 87: 122- 125.

43. Katiyar, S. K. and Mukhtar, H. (1996) Tea in chemoprevention of cancer: Epidemiologic and experimental studies, Int JOncology, 8:221- 238.

44. Yan, X., Murphy, B. T., Hammond, G. B., Vinson, J. A. and Neto, C. C. (2002) Antioxidant activities and anti-tumor screening of extracts from cranberry fruit (Vaccinium macrocarpon), JAgric Food Chem, 20: 5844-49.

45. Chen, Z. Y., Wang, L. Y., Chan, P. T., Zhang, Z. S., Chung, H. Y. and Liang, B. (1998) Antioxidative activity of green tea catechin extract compared with that of rosemary extract, $J$ American Oil Chemists'Soci, 75: 1141- 1145.

46. Tang, S., Sheehan, D., Buckley, D. J., Morrissey, P. A. and Kerry, J. P. (2001) Anti-oxidant activity of added tea catechins on lipid oxidation of raw minced red meat, poultry and fish muscle, Int JFood Sci Technol, 36: 685- 692.

47. Bozkurt, H. (2006) Utilization of natural antioxidants: green tea extract and Thymbra spicata oil in Turkish dry-fermented sausage, Meat Sci, 73: 442- 450.

48. Choi, S. H., Kwon, H. C., An, D. J., Park, J. R. and Oh, D. H. (2003) Nitrite contents and storage properties of sausage added with green tea powder, Korean J Food Sci Ani Res, 23: 299- 308.

49. Sarker, M. S. K., Yim, K. J., Ko, S. Y., Uuganbayar, D., Kim, G. M., Bae, I. H., Oh, J. I., Yee, S. T. and Yang, C. J. (2010) Green Tea Level on Growt Performance and Meat Quality in Finishing Pigs, PakJ Nutr, 9 (1): 10-14.

50. Lau, D. W. and King, A. J. (2003) Pre and post-mortem use of grape seed extract in dark poultry meat to inhibit development of thiobarbituric acid reactive substances, J Agri Food Chemistry, 51: 1602- 1607.

51. Brannan, R. G. and Mah, E. (2007) Grape seed extract inhibits lipid oxidation in muscle from different species during refrigerated and frozen storage and oxidation catalyzed by peroxynitrite and iron/ascorbate in a pyrogallol red model system, Meat Sci, 77: 540- 546.

52. Banon, S., Diaz, P., Rodriguez, M., Garrido, M. D. and Price, A. (2007) Ascorbate, green tea and grape seed extracts increase the shelf life of low sulphite beef patties, Meat Sci, 77: 626- 633.

53. Brannan, R. G. (2009) Effect of grape seed extract on descriptive sensory analysis of ground chicken during refrigerated storage, Meat $S c i, 81: 589$ - 595.

54. Carpenter, R., O'Grady, M. N., O'Callaghan, Y. C., O'Brien, N. M. and Kerry, J. P. (2007) Evaluation of the antioxidant potential of grape seed and bearberry extracts in raw and cooked pork, Meat Sci, 76: 604- 610.

55. Mielnik, M. B., Olsen, E., Vogt, G., Adeline, D., and Skrede, G. (2006) Grape seed extract asantioxidant in cooked, cold stored turkey meat, Food Sci Technol,39:191- 19.

56. Rababah, T., Hettiarachchy, N. S., Horax, R., Cho, M. J., Davis, B. and Dickson, J. (2006) Thiobarbituric acid reactive substances and volatile compounds in chicken breast meat infused with plant extracts and subjected to electron beam irradiation, Poultry Sci, 85(6): 1107- 1113.

57. Rojas, M. C. and Brewer, M. S. (2007) Effect of natural antioxidants on oxidative stability of cooked, refrigerated beef and pork. J Food Sci, 72(4), 282- 288.

58. Hertog, M. G. L. and Katan, M. B. (1998) Quercetin in foods, cardiovascular disease, and cancer. In: Flavonoids in health and disease, Rice-Evans CA, Packer L, (eds). New York Marcel Dekker Inc. pp 447-467.

59. Starvic, B. (1984) Mutagenic food flavonoids, Fed Proc 43: 2344.
$* * * * * * * *$ 